\title{
Molecular Evidence that the Extracellular Cutinase Pbc1 Is Required for Pathogenicity of Pyrenopeziza brassicae on Oilseed Rape
}

\author{
Donghui Li, Alison M. Ashby, and Keith Johnstone \\ Department of Plant Sciences, University of Cambridge, Downing Street, Cambridge CB2 3EA, U.K.
}

Submitted 19 August 2002. Accepted 10 February 2003.

\begin{abstract}
Recent evidence has suggested that cutinase is required for cuticular penetration and, therefore, is essential for pathogenicity of Pyrenopeziza brassicae, the causal organism of light leaf spot disease of oilseed rape and other brassicas. In order to acquire molecular evidence for the role of cutinase in pathogenesis, the single-copy $P$. brassicae cutinase gene $P b c 1$ was disrupted by a transformation-mediated approach. Southern hybridization analysis revealed that in one mutant, NH10-1224, the disruption was due to a tandem insertion of two copies of the disruption vector into the $5^{\prime}$ coding region of $\mathrm{Pbc1}$. In contrast to the wild type, no expression of $\mathrm{Pbc1}$ was detected during in planta growth or in cutin-induced mycelium of NH10-1224 and no cutinase activity was detected in culture supernatants from NH10-1224 using pnitrophenyl butyrate as substrate. Scanning electron microscopy of Brassica napus cotyledons infected with wild-type $P$. brassicae confirmed that entry into the host is by direct penetration of the cuticle. In contrast, the cutinase-deficient mutant NH10-1224 failed to penetrate the cuticular layer and was unable to develop disease symptoms. This evidence is consistent with the hypothesis that $P b c 1$ is required for $P$. brassicae to penetrate the plant cuticle. Demonstration that complementation of $\mathrm{NH10-1224}$ with the $\mathrm{Pbcl}$ wild-type gene restores both cutinase activity and pathogenicity will be required to definitively establish that cutinase is required for successful pathogenesis of brassicas by $\boldsymbol{P}$. brassicae.
\end{abstract}

The plant cuticle is a major structural barrier that many fungi, which infect the aerial parts of plants, must breach in order to successfully invade their host (Kolattukudy 1985). The cuticle contains the insoluble polymer cutin, which consists of hydroxy and epoxy fatty acids linked together by ester bonds (Baker 1982; Holloway 1982; Kolattukudy et al. 1981). Fungal pathogens have evolved a number of different strategies to penetrate the plant cuticle. Some fungal pathogens, such as the rice blast fungus Magnaporthe grisea, penetrate the cuticle directly by mechanical force with the aid of specialized infection structures called appressoria (Dean 1997; DeJong et al. 1997). Alternatively, it has been proposed that penetration could be achieved by degradation of the cutin polymer by serine esterases which are members of the $\alpha / \beta$ hydrolase fold family of lipases (Longhi and Cambillau 1999) and which are referred to collectively as cutinases (Kolattukudy 1984). The role of cutinases in cuticular penetration by fungal pathogens has been the subject of considerable debate (Annis and Goodwin 1997; Lebeda et

Corresponding author: Keith Johnstone; Telephone: 44-1223-333933; Fax: 44-1223-333953; E-mail: kj10@cam.ac.uk al. 2001; Rogers et al. 1994; Stahl and Schäfer 1992; Stahl et al. 1994). In the case of fungi that penetrate the cuticle directly, there is substantial evidence that cutinase plays a crucial role during this process and is therefore an important pathogenicity determinant (Kolattukudy 1985). For example, cutinase has been found at the site of penetration of pea by Fusarium solani f. sp. pisi (Shaykh et al. 1977). In addition, cutinase antibodies prevented infection of pea stems with intact cuticles by $F$. solani f. sp. pisi (Maiti and Kolattukudy 1979) and the inhibitor diisopropylflurophosphate suppressed lesion formation by $\mathrm{Col}$ letotrichum gloeosporioides in papaya (Dickman et al. 1982). Also, mutants of F. solani f. sp. pisi and C. gloeosporioides with reduced cutinase activity showed decreased virulence (Dantzig et al. 1986; Dickman and Patil 1986). Furthermore, heterologous transformation of the F. solani cutinase gene into Mycosphaerella, a pathogen that normally infects only wounded papaya fruit, enabled it to infect the intact host (Dickman et al. 1989). However, recent gene disruption studies, for example in $F$. solani (Stahl and Schäfer 1992; Stahl et al. 1994), M. grisea (Sweigard et al. 1992b), and Botrytis cinerea (Van Kan et al. 1997), have produced conflicting evidence, suggesting that cutinase is not required for fungal pathogenicity.

Pyrenopeziza brassicae, which causes light leaf spot disease of brassicas, is a haploid, heterothallic, hemibiotrophic discomycete member of the division Ascomycotina (Ashby 1997; Rawlinson et al. 1978; Singh and Ashby 1998). There are several lines of evidence that suggest a role for cutinase in pathogenicity. First, appressoria have not been observed and hyphae do not enter the leaf through stomata, but directly penetrate the cuticle. From microscopic studies of the sites of pathogen ingress, it appeared that enzymatic degradation of the cuticle might be important in facilitating penetration (Maddock 1979; Rawlinson et al. 1978). Second, treatment of spores with the serine esterase inhibitors ebelactones A and B resulted in a marked decrease in pathogenicity of $P$. brassicae on oilseed rape (Davies et al. 2000). Furthermore, following induction in vitro with apple cutin, $P$. brassicae produces a single extracellular esterase with cutinolytic activity (Davies et al. 2000). The corresponding cutinase gene, designated $\mathrm{Pbcl}$, shows high similarity at the amino acid level to the cutinases of $B$. cinerea and other filamentous fungi (Davies et al. 2000).

In order to provide molecular evidence for a requirement of cutinase for pathogenicity of $P$. brassicae on brassicas, the $P b c 1$ gene was disrupted by a transformation-mediated approach and the effect of this disruption on symptom development was studied. We show that disruption of $P b c l$ in a single mutant results in loss of ability of $P$. brassicae to produce extracellular cutinase activity in vitro, as well as the ability to pathogenize the host plant. 


\section{RESULTS}

Cutinase gene disruption.

In order to disrupt the single copy $P$. brassicae cutinase gene $P b c 1$, we used the disruption vector pIM, in which a 185-bp internal fragment of the $P b c l$ coding region had been inserted into the HindIII site of pAN7-1, which carries the selectable marker hygromycin B phosphotransferase ( $h p h)$ conferring hygromycin B resistance (Punt et al. 1987) (Fig. 1). pIM was transformed into $P$. brassicae isolate $\mathrm{NH} 10$ using a transformation procedure modified from that of Ball and associates (1991). The isolate NH10 was chosen for these studies because it contains a single copy of Pbcl (Davies et al. 2000) and is highly pathogenic on oilseed rape (Ball et al. 1992). Disruption

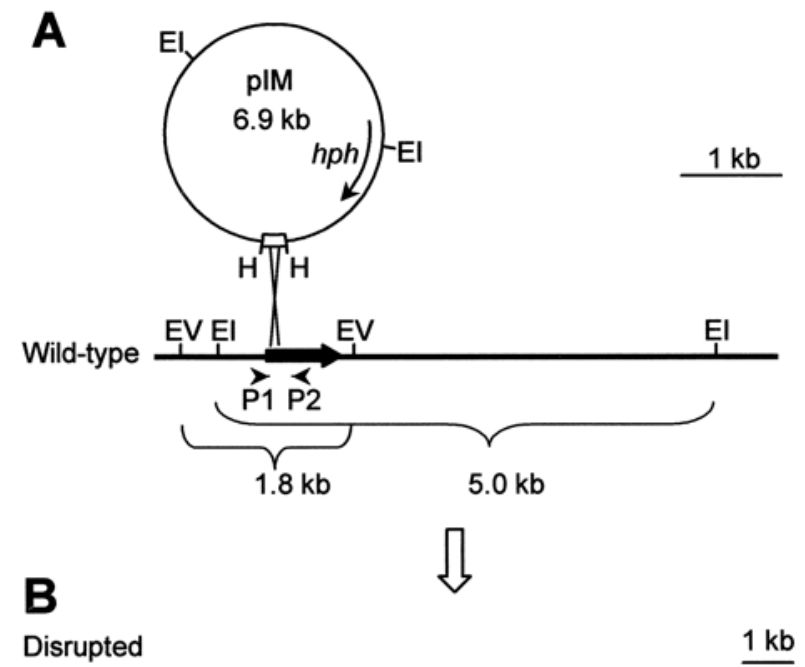

1 Single homologous recombination

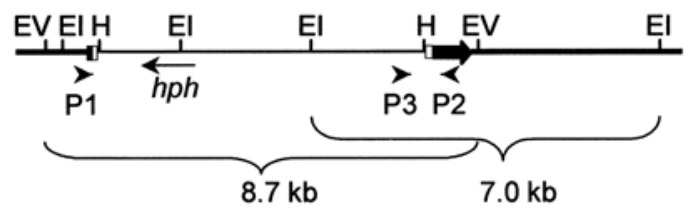

2 Tandem insertion ( 2 copies)

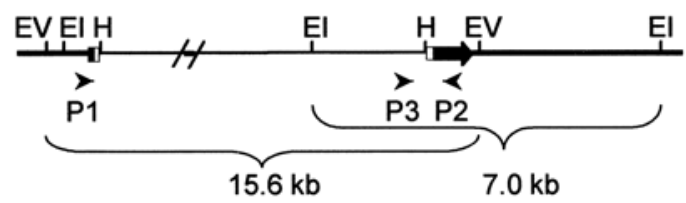

C

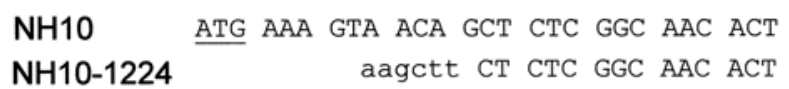

Fig. 1. Targeted disruption of the Pyrenopeziza brassicae cutinase gene $P b c 1$. A, Plasmid pIM contains an internal fragment (open box) from the coding region of $\mathrm{Pbcl}$ and a selectable marker hygromycin phosphotransferase gene $(h p h)$. B, Integration of one or more copies of pIM by homologous recombination into the $P b c l$ coding region (solid arrow) results in insertional inactivation of the $P$. brassicae cutinase gene. C, Sequence comparison showing the insertion of pIM into the $5^{\prime}$ coding region of $P b c l$ in NH10-1224. The $P b c l$ start codon is underlined in the NH10 sequence, the HindIII site of the disruption vector PIM is in lower case. EI, EcoRI; EV, EcoRV; and H, HindIII. The predicted EcoRI and $E c o R V$ fragment sizes are shown in $\mathbf{A}$ for the intact cutinase gene and $\mathbf{B}$ following gene disruption. The positions and orientations of primers P1, P2, and P3 used for selection of the Pbcl-disrupted transformants are indicated by arrows. of the target gene and introduction of hygromycin B resistance can be achieved by integration of one or more copies of the disruption vector into the fungal genome by homologous recombination (Fig. 1). A total of 375 hygromycin B-resistant transformants were screened for gene disruption by the polymerase chain reaction (PCR) using primers $\mathrm{P} 1$ and $\mathrm{P} 2$, which are homologous to regions that flank the 185-bp $\mathrm{Pbcl}$ internal fragment (Fig. 1). Of the transformants screened, 361 produced the same 681-bp PCR product as the wild-type isolate NH10, demonstrating that they contained an intact $\mathrm{Pbcl}$ locus (data not shown). In these transformants, the pIM vector presumably had inserted ectopically into the genome. The absence of the 681-bp PCR product from the other 14 transformants suggested that they were putative $\mathrm{Pbcl}$-disrupted mutants. PCR using the $P$. brassicae diagnostic primers $\mathrm{Pb} 1$ and $\mathrm{Pb} 2$ (Foster et al. 1999) was used to confirm the validity of the PCR screening and generated the expected 750-bp product in 13 out of 14 transformants (data not shown). Analysis of the remaining 14 putative cutinase gene disruption mutants by Southern hybridization analysis revealed that, in one transformant, designated NH10-1224, disruption had occurred within the Pbcl locus (Fig. 2).

In order to characterize the insertion event in NH10-1224, EcoRV and EcoRI digests of genomic DNA from NH10 and NH10-1224 were probed with Pbcl. As expected, the wildtype NH10 showed single hybridization bands of 1.8 and 4.7 kb after digestion with EcoRV and EcoRI, respectively (Figs. 1 and 2A). However, in the case of NH10-1224, the EcoRV hybridizing band had increased in size from 1.8 to $15.6 \mathrm{~kb}$. EcoRV does not cut within pIM $(6.9 \mathrm{~kb})$; therefore, these results suggested that two copies of pIM had inserted into the Pbcl locus. A 7.0-kb band was observed in the EcoRI digest of DNA from NH10-1224, which is consistent with that expected for homologous integration of pIM into Pbcl (Figs. 1 and 2A). In order to confirm that integration of pIM had occurred at a single site in the NH10-1224 genome, the EcoRV digests also were probed with the vector pAN7-1. A single hybridizing band of $15.6 \mathrm{~kb}$ band was present in the mutant, indicating that no extra copies of pIM had inserted into the genome other than at the $\mathrm{Pbcl}$ locus (Fig. 2B). To determine the integration point of pIM within $P b c l$, the junction between the disruption vector and the Pbcl locus in NH10-1224 was amplified by PCR using primers P2 and P3 (Fig. 1B) and then directly sequenced using the same primers. The results confirmed that pIM had inserted into the $5^{\prime}$ coding region of $\mathrm{Pbcl}$ (Fig. 1C). We conclude that NH10-1224 is a cutinase gene disruption mutant resulting from a tandem insertion of two copies of pIM into the $\mathrm{Pbcl}$ coding region.

No differences were observed when the in vitro colony morphology, growth rate, sporulation frequency, conidial size, and conidial germination characteristics of NH10-1224 and NH10 grown on malt extract agar (MA) were compared (data not shown). Assessment of mitotic stability as described by Ball and associates (1991) showed that the inserted disruption vector stably existed in NH10-1224 after at least four rounds of culturing on nonselective medium (data not shown).

\section{Transcriptional and enzymatic analysis of the $P$. brassicae cutinase.}

Cutinase induction in P. brassicae isolate NH10-1224 in the presence of apple cutin was analyzed. Mycelium of the cutinase mutant NH10-1224 and of the wild-type isolate $\mathrm{NH} 10$ were grown in minimal medium with apple cutin as the sole carbon source. Total RNA was isolated from the mycelium and the expression of $\mathrm{Pbcl}$ in these isolates was tested by reverse transcription-PCR (RT-PCR) using the $P b c l$ gene specific primers P4 and P5. A low level of $\mathrm{Pbcl}$ transcript was detected 
in the uninduced wild-type NH10, which presumably reflects a basal level of expression (Fig. 3); following induction with apple cutin, the amount of $\mathrm{Pbcl}$ transcript increased in NH10 (Fig. 3). These results were consistent with previous Northern blot analysis of cutinase gene expression in $P$. brassicae (Davies et al. 2000). In contrast, no Pbcl transcript was detected in vitro from either uninduced or induced mycelium of NH10-1224. RNA isolated from B. napus cotyledons (cv. Bristol) infected with NH10 or NH10-1224 also was analyzed by RT-PCR in order to examine the expression of $\mathrm{Pbcl}$ in planta. The results revealed the presence of the $P b c l$ transcript in NH10-infected cotyledons (Fig. 3). Conversely, no Pbcl transcript was detected from cotyledons infected with NH10-1224. The same first-strand cDNA samples also were subjected to PCR using primers derived from the constitutively expressed GAPDH gene (Singh 1998) to confirm the integrity of the RNA samples used (Fig. 3).

Quantitative analysis of cutinase activity in cutin-induced liquid culture as measured by p-nitrophenyl butyrate (PNB) esterase activity (Kolattukudy et al. 1981) showed that the levels of cutinase activity in culture supernatants of the wild-type NH10 increased with time after induction, whereas no significant cutinase activity was detected in the cutinase gene-disrupted mutant NH10-1224 (Fig. 4). The ability of NH10-1224 to produce extracellular cutinase also was tested using a plate assay. Mycelial blocks of both NH10 and NH10-1224 were plated onto minimal medium supplemented with apple cutin as the sole carbon source. After incubation for 3 weeks, the colonies were overlaid with agarose containing PNB. A yellow halo indicating extracellular cutinase activity surrounded the wildtype NH10 colony, whereas no halo was observed for the mutant (data not shown). In addition, NH10-1224 showed very little mycelial growth on this medium in comparison with NH10, providing further evidence that this mutant lacked the ability to degrade the cutin carbon source. On the basis of these results, and the knowledge that $P$. brassicae contains a single cutinase encoded by $\mathrm{Pbcl}$, we conclude that NH10-1224 is an extracellular cutinase-deficient mutant.

\section{Pathogenicity of NH10-1224.}

In order to analyze the effect of disruption of $\mathrm{Pbcl}$ on the ability of $P$. brassicae to infect its host, a cotyledon-based pathogenicity test (Ball et al. 1992) was performed using conidia of NH10-1224. Cotyledons of the susceptible oilseed rape cultivar Bristol were inoculated with $10 \mu$ of conidial suspension $\left(1 \times 10^{6}\right.$ conidia $\left.\mathrm{ml}^{-1}\right)$, incubated, and examined microscopically over a period of 4 weeks to study cuticular penetration and the development of disease symptoms. Conidia of NH10 were deposited preferentially over the anticlinal walls of epidermal cells and produced relatively short germ tubes which directly penetrated the host surface (Fig. 5A). These observations are consistent with those of Davies and associates (2000). Conidia of NH10-1224 were able to germinate on the plant surface but were unable to penetrate the cuticle; however, slight hyphal swellings were observed, which may represent failed penetration attempts (Fig. 5B). After penetration, the wild-type NH10 established extensive subcuticular growth (Fig. 5C and E). In contrast, hyphae were observed on the surface of NH101224-infected cotyledons, but no subcuticular growth was observed (Fig. 5D and F). From 15 days onward, NH10 produced acervular conidiomata bearing hundreds of conidia which ruptured the host cuticle (Fig. 5G and I); this is the most characteristic symptom of light leaf spot disease. In four independent cotyledon tests ( 25 cotyledons per experiment), $90 \pm 5 \%$ of the cotyledons infected with NH10 showed erumpent conidiomata at 21 days post inoculation, whereas no conidiomata were formed on the surfaces of the cotyledons infected with NH10-
1224 (Fig. 5H and J). The NH10-1224-infected cotyledons were incubated for a further 7 days and no conidiomata were observed.

In order to confirm that the disruption vector pIM was not lost during growth of NH10-1224 in the pathogenicity test, PCR analysis was performed on total genomic DNA extracted from infected cotyledons using combinations of primers $\mathrm{P} 1$, P2, and P3 (Figs. 1 and 6). In the case of NH10 infection, PCR with primers P1 and P2 yielded the expected 681-bp product, which was not detected in an identical PCR reaction from cotyledons infected with NH10-1224 (Fig. 6). Only NH10-1224infected cotyledons yielded a 1,034-bp product with primers P2 and P3 (which encompasses the integration site of the disruption vector $\mathrm{pIM}$ ). Therefore, it is concluded that no loss of pIM occurred from NH10-1224 during the pathogenicity test.

We also tested the pathogenicity of another transformant, designated NH10-1024, which contained pIM ectopically integrated at a single locus. Symptomatic infection was obtained in the detached cotyledon test after 3 weeks (data not shown), indicating that, in this case, ectopic integration of pIM into the $P$. brassicae genome had no effect on pathogenicity; this is consistent with previous results reported by Ball and associates (1991).

These results are consistent with the hypothesis that expression of the extracellular cutinase Pbc1 is required for successful penetration of the host cuticle by $P$. brassicae and, consequentially, for the subsequent development of disease symptoms.

\section{DISCUSSION}

In this study, we present molecular evidence that the extracellular cutinase encoded by $P$. brassicae $P b c l$ is required for pathogenicity on $B$. napus. Although the simplest explanation of the phenotype of NH10-1224 is that loss of cutinase activity and pathogenicity are due to the same disruption event in $\mathrm{Pbcl}$, the results should be interpreted with caution. Other possible explanations of the phenotype of NH10-1224 include a second independent mutagenic event or the polar effect of an integration event in the $\mathrm{Pbcl}$ locus, both of which could influence expression of an as-yet-unidentified gene required for pathogenicity. Definitive proof of the role of cutinase in pathogenic-

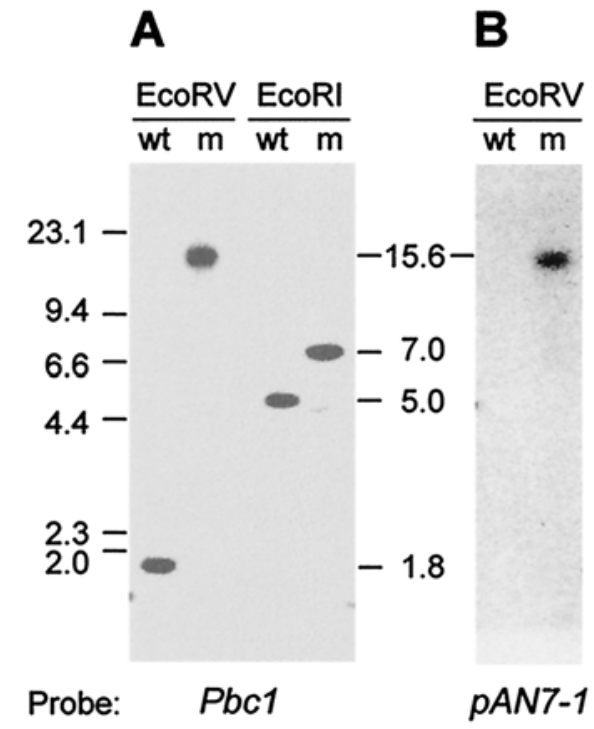

Fig. 2. Southern hybridization analysis of wild type and $P b c 1$ mutant. EcoRV and EcoRI digests of genomic DNA from NH10 (wt) and NH101224 (m) were probed with $\mathbf{A}, P b c 1$ and $\mathbf{B}$, pAN7-1, respectively, as described in Methods. Numbers indicate the sizes of Lambda HindIII markers in kilobases (left of A) and hybridization bands (left of B). 
ity of $P$. brassicae will, therefore, require demonstration that complementation of NH10-1224 with the $P b c l$ wild-type gene concomitantly restores both cutinase activity and pathogenicity. The $P b c l$ transcript was present in elevated levels in response to growth on cutin as the sole carbon source and also was present during growth in planta. A basal level of cutinase transcript activity was observed prior to induction in vitro, supporting the "cutinase concept" proposed by Kolattukudy and associates (1989). According to this concept, basal cutinase activity released from the fungal spore triggers the release of cutin monomers which, in turn, further induce the fungal cutinase gene, thereby facilitating cuticular penetration.

In the last decade, the use of molecular approaches has brought into question the role of cutinases produced by plantpathogenic fungi. It is becoming clear that no general model can be applied and that there is a need to evaluate the role of cutinase in pathogenicity of each host-pathogen interaction. There is some evidence that the role of cutinase may reflect the mode of nutrition of the fungus in its natural environment (Köller et al. 1995). For those fungi adopting primarily saprophytic modes of nutrition in planta, it has been suggested that cutinase may be crucial for the utilization of cutin from decaying plant material. Mutations in the cutinase genes of the predominantly saprophytic fungi $F$. solani f. sp. pisi and Alternaria brassicicola resulted in the impairment of saprophytic growth on cutin rather than loss of ability to infect the plant (Stahl and Schäfer 1992; Yao and Koller, 1995). In contrast, it has been proposed that the cutinase/serine esterases of the obligate biotrophic rust parasite Uromyces viciae-fabae is involved in the formation of adhesion pads on bean (Deising et al. 1992). Similarly, cutinases were found within conidial exudates of the hemibiotrophic fungal pathogen $C$. graminicola (Pascholati et al. 1993) and the obligate biotroph Erysiphe graminis f. sp. hordei (Pascholati et al. 1992), possibly suggesting a role for cutinase in adhesion of these obligate phytopathogens to their respective host plants. Furthermore, a role of cutinase in appressorial germ tube development in E. graminis f. sp. hordei has been proposed (Francis et al. 1996). In the hemibiotrophic apple scab pathogen, Venturia inaequalis, an extracellular cutinase has been implicated in subcuticular growth of the fungus in planta (Köller et al. 1991). It is interesting to note that this fungus only infects juvenile leaves where the cuticle is thinner and is unable to penetrate older

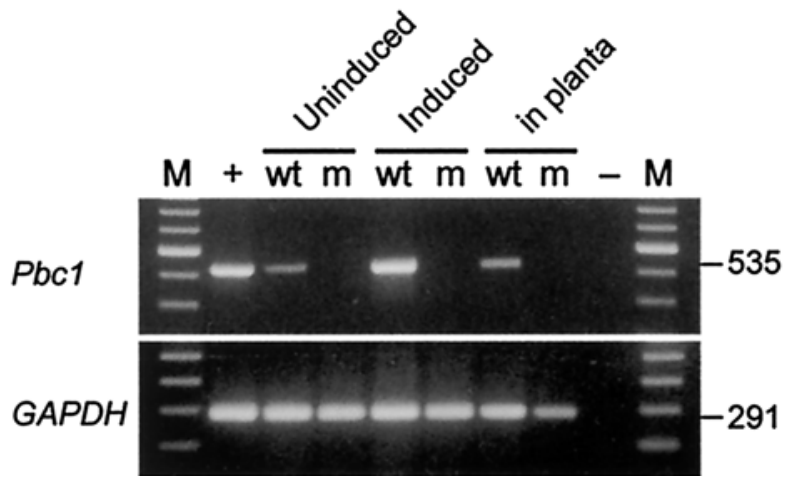

Fig. 3. Expression analysis of $P b c 1$. Reverse transcriptase-polymerase chain reaction (RT-PCR), showing the absence of the $P b c 1$ transcript in the mutant NH10-1224 and its presence in the wild-type NH10 when grown under in vitro and in planta conditions. RNA was isolated from NH10 (wt) and NH10-1224 (m) grown either in vitro (uninduced or induced with cutin) or in planta (on Brassica napus cotyledons) and RTPCR performed using gene-specific primers for $P b c l$ and $G A P D H$ as described in the Methods. $+=P b c 1$ or $G A P D H$ cDNA clone as template; - = water only; $\mathrm{M}=100$-bp DNA ladder (Invitrogen, Paisley, UK). The sizes of the PCR products are shown in base pairs. leaves that have a much thicker cuticle (Nicholson et al. 1973a,b). A further role for cutinases was proposed more recently and involves protection of the host plant. The lipolytic activity of cutinase purified from $V$. inaequalis was shown to protect bean leaves from infection by Rhizoctonia solani (Parker and Köller 1998), presumably by the release of fungitoxic cutin monomers. Similarly, certain cutin monomers were shown to be fungitoxic to tomato powdery mildew infection (Wang et al. 2000).

Here, we have provided evidence that the hemibiotroph $P$. brassicae produces a cutinase that is involved in direct penetration of the host cuticle. A subsequent role in subcuticular growth, as proposed for V. inaequalis (Köller et al. 1991), is also possible, because the fungus grows preferentially within the subcuticular space with little or no penetration of cells within the mesophyll (Ashby 1997) and because a Pbcl transcript was observed during in planta growth.

To date, all of the cutinase genes that have been cloned were obtained following purification of enzymes that were preferentially expressed during saprophytic growth (Ettinger et al. 1987; Soliday et al. 1984; van der Vlugt-Bergmans et al. 1997) or were obtained following molecular analysis of sequence similarity between saprophytically expressed cutinase genes (Davies et al. 2000; Ettinger et al. 1987; Sweigard et al. 1992a; Yao and Köller 1994). In the cases where gene knockouts were tested, direct molecular evidence failed to establish a definitive role for cutinase in pathogenicity (Köller et al. 1995; Stahl and Schäfer 1992; Sweigard et al. 1992b; Van Kan et al. 1997); therefore, a saprophytic role for these enzymes was suggested. Therefore, there may be additional cutinases, such as those identified by Yao and Koller (1995), that have evolved primarily to function during pathogen ingress in a rapid and localized manner, unlike their saprophytic counterparts, whose role would involve the more widespread liberation of fatty acids from the cutin polymer during growth on decaying plant debris. Here, we have presented evidence for a gene expressed during in vitro growth on cutin that has a direct role in pathogenicity. This may reflect the nutritional mode of the fungus; $P$. brassicae has many features in common with an obligate parasite, unlike the fungi in which previous cutinase gene knockouts were performed. $P$. brassicae produces a relatively short germ tube that directly penetrates the host cuticle (Maddock 1979). Subsequent growth and development is entirely subcuticular, resulting in the formation of acervular conidiomata or, upon senescent tissue or debris and in the presence of the op-

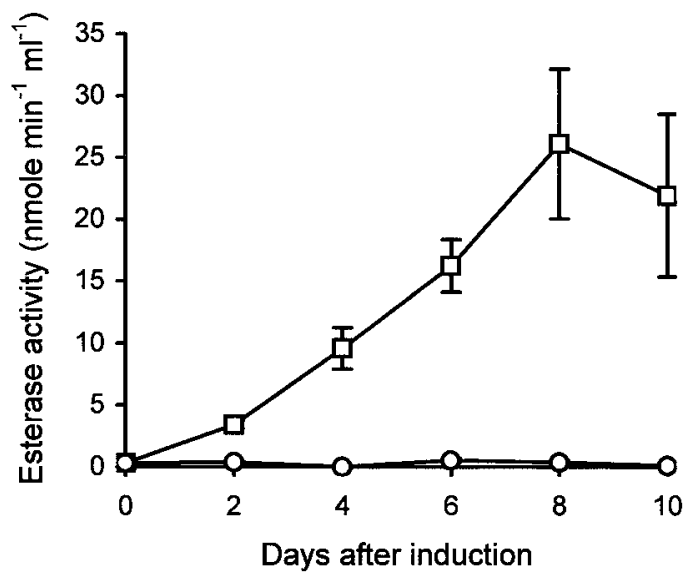

Fig. 4. Induction of cutinase activity in Pyrenopeziza brassicae isolates NH10 $\left({ }^{\mathrm{TM}}\right)$ and NH10-1224 (O) when grown on cutin, as measured by the p-nitrophenyl butyrate esterase activity. The results show means \pm SD for three independent experiments. 
posite mating type, the formation of apothecia (Gilles et al. 2001). The requirement for saprophytic growth of $P$. brassicae is minimal: its life cycle occurs almost entirely within the plant, apart from the release of conidia from acervulae and ascospores from apothecia, which occur following rupture of the host cuticle to expose developmental structures (Ashby 1997). In fact, due to its relatively slow growth rate in vitro, it is unlikely that $P$. bras sicae would compete well for nutrients within competitive environments such as the phylloplane. Access to the internal plant environment, where competition would be greatly reduced, is, therefore, likely to be a prerequisite for survival of this organism. Furthermore, it has been observed that a direct correlation be-
Wild-type $\mathrm{NH} 10$
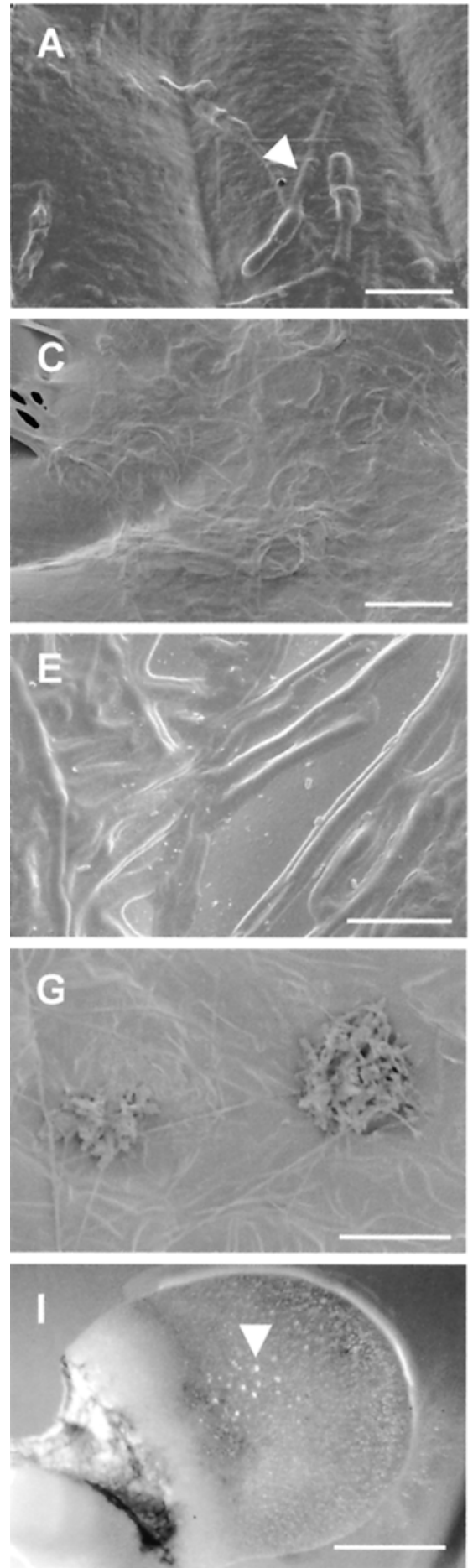

Mutant $\mathrm{NH} 10-1224$
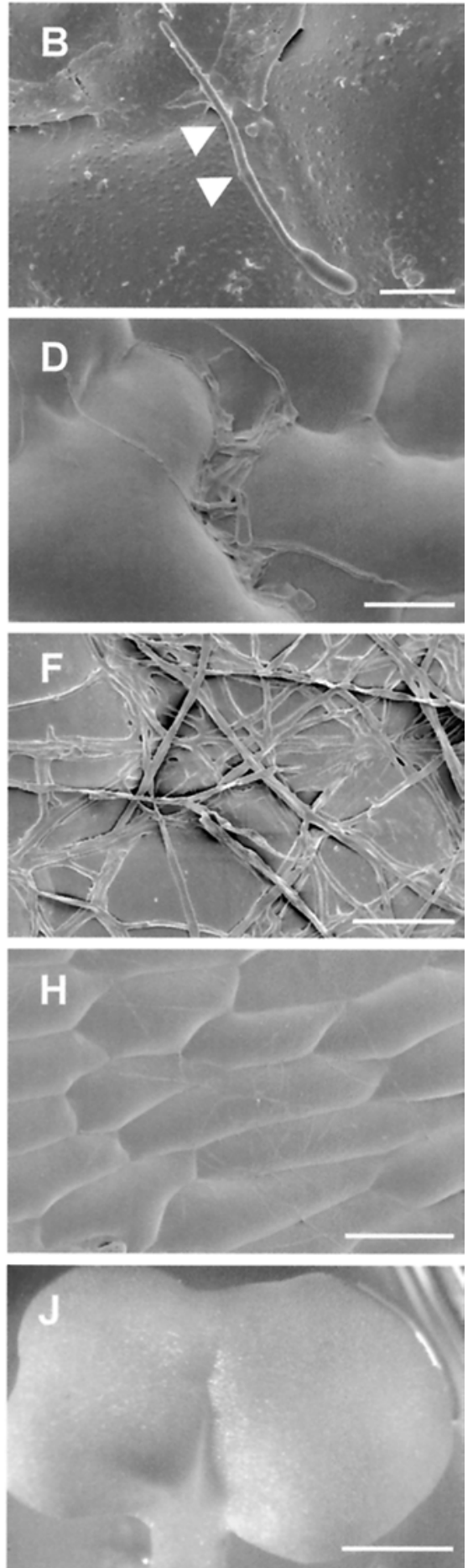

Fig. 5. Microscopic analysis of Brassica napus cotyledons infected with NH10 or NH10-1224. A to $\mathbf{H}$ are scanning electron micrographs; A, showing Pyrenopeziza brassicae entering the host by direct cuticular penetration 2 days post inoculation (dpi); (arrows show penetration sites) and $\mathbf{C}$ and $\mathbf{E}$, establishing extensive subcuticular growth. In contrast, B shows NH10-1224 failing to penetrate the cuticle (arrows depict points of hyphal swelling) and $\mathbf{D}$ and $\mathbf{F}$, no subcuticular growth was observed. At 21 days, the characteristic erumpent acervular conidiomata were observed in $\mathbf{G}$, the wild-type infected cotyledons. H, No acervular conidomata were observed for NH10-1224. I and J, Photomicrographs of cotyledons inoculated with I, NH10 and J, NH101224 at 21 dpi. I, The wild-type infection shows the characteristic white spotting (arrow) caused by erumpent acervular conidiomata. J, No symptoms were observed for NH10-1224. Bar represents $10 \mu \mathrm{m}$ (A and B), $20 \mu \mathrm{m}(\mathrm{C}-\mathrm{F}), 50 \mu \mathrm{m}(\mathrm{G}), 100 \mu \mathrm{m}(\mathrm{H})$, and $5 \mathrm{~mm}(\mathrm{I}$ and $\mathrm{J})$. 
tween cuticle topology and resistance rating exists, with those cultivars displaying higher resistance to $P$. brassicae having thicker, more waxy cuticles (Davies 1997), implicating the requirement of a cutinase for successful penetration of the host.

We currently are seeking to complement NH10-1224 as well as studying expression of $\mathrm{Pbcl}$ during in planta growth and evaluating cutinase as a novel validated target for the control of light leaf spot disease of brassicas.

\section{MATERIALS AND METHODS}

\section{Fungal isolates.}

P. brassicae isolate NH10 (Simons and Skidmore 1988) was maintained on MA containing 3\% (wt/vol) Oxoid malt extract and $1.2 \%$ (wt/vol) Difco bacto-agar at $18^{\circ} \mathrm{C}$ in the dark. Hygromycin B-resistant transformants, including NH10-1224 and NH10-1024, were grown on malt extract agar containing hygromycin B at $16 \mu \mathrm{g} \mathrm{ml}^{-1}$.

\section{Cutinase gene disruption.}

For gene disruption, the vector pIM was constructed. A 185bp internal fragment of the $P$. brassicae cutinase gene $P b c 1$ (EMBL accession number AJ009953; nucleotide positions 14 to 198) was amplified from plasmid pKD1 (Davies et al. 2000) using the following primers: a 30-mer GAGAGAAAGCTTCTCTCGGCAACACTCTCA and a 33-mer GAGAGAAAGCTTCCCCATCATAACCTCCAA. These primers contain a HindIII cleavage site (underlined). After digestion with HindIII, the fragment was ligated into the HindIII site of pAN7-1 (Punt et al. 1987), resulting in the disruption vector pIM. Correct insertion of the 185-bp Pbcl fragment into pAN7-1 was confirmed by direct plasmid sequencing.

Fungal transformation was carried out according to Ball and associates (1991) with the following modifications. First, conidia were examined microscopically every $30 \mathrm{~min}$ during Novozyme 234 digestion until $95 \%$ had converted to protoplasts (approximately $60 \mathrm{~min}$ ). Second, the transformation mixture was added to malt-sorbitol top agar (Ball et al. 1991) at $38^{\circ} \mathrm{C}$ rather than $48^{\circ} \mathrm{C}$. Typically, 40 to 120 transformants per microgram of vector DNA were obtained from $10^{6}$ protoplasts.

\section{Screening}

for cutinase gene-disrupted transformants by PCR.

Hygromycin B-resistant transformants were screened for gene disruption by the PCR. Genomic DNA was extracted ac-

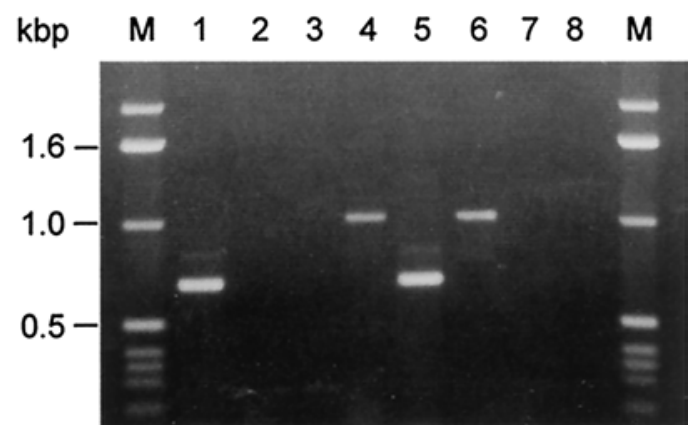

Fig. 6. Stability of pIM in NH10-1224 in the pathogenicity test. Polymerase chain reaction (PCR) of genomic DNA from cotyledons infected with NH10 (lanes 1 and 2) and NH10-1224 (lanes 3 and 4) using the primer pairs $\mathrm{P} 1$ and $\mathrm{P} 2$ (lanes 1 and 3 ) and $\mathrm{P} 2$ and $\mathrm{P} 3$ (lanes 2 and 4). Genomic DNA from NH10 (lane 5, primers P1 and P2) and NH10-1224 (lane 6, primers $\mathrm{P} 2$ and $\mathrm{P} 3$ ) was used as positive controls. PCR of uninfected Brassica napus cotyledons using primers P1 and P2 (lane 7) and P2 and P3 (lane 8) were used as negative controls. $\mathrm{M}=1$-kb DNA ladder (Invitrogen, Paisley, U.K.). Sizes of the PCR products are shown in kilobase pairs (kbp). cording to Lee and Taylor (1990). The primers P1 (5'CATGGCTCCAGTAATCAAC-3') and P2 (5'-TCTCGAATAGGTAAGATGCTCG-3'), corresponding to nucleotide positions -19 to -1 and 661 to 640 of $P b c l$, respectively, were used in PCR to amplify a 681-bp genomic DNA fragment of the cutinase gene. The absence of this amplicon indicated a putative gene disruption event. PCR was set up in a 50- $\mu$ l reaction volume containing: $5 \mu \mathrm{l}$ of $10 \times$ Reaction buffer $(160 \mathrm{mM}$ $\left[\mathrm{NH}_{4}\right]_{2} \mathrm{SO}_{4}, 670 \mathrm{mM}$ Tris- $\mathrm{HCl}, \mathrm{pH} 8.8,0.1 \%$ Tween-20); $5 \mu \mathrm{l}$ of $50 \mathrm{mM} \mathrm{MgCl} 2 ; 5 \mu \mathrm{l}$ of $2 \mathrm{mM}$ dNTPs; $1 \mu \mathrm{l}$ of each primer $\left(100\right.$ pmoles $\left.\mu^{-1}\right)$; 200 ng of genomic DNA; and 1.5 units of BioTaq DNA polymerase (Bioline, London). Amplifications were performed with 3 min of initial denaturation at $94^{\circ} \mathrm{C} ; 30$ cycles of $1 \mathrm{~min}$ of denaturation at $94^{\circ} \mathrm{C}, 1 \mathrm{~min}$ of annealing at $55^{\circ} \mathrm{C}$, and $1 \mathrm{~min}$ of extension at $72^{\circ} \mathrm{C}$, followed by a final extension of $3 \mathrm{~min}$ at $72^{\circ} \mathrm{C}$. As positive controls, aliquots of the same genomic DNA samples also were tested with the P. brassicae diagnostic primers $\mathrm{Pb} 1$ and $\mathrm{Pb} 2$ to amplify a 750-bp PCR product (Foster et al. 1999).

Primers P3 (5'-GACGGTGAAAACCTCTGAC-3', corresponding to nucleotide positions 4,490 to 4,508 of pAN7-1) (Punt et al. 1987) and P2 were used with NH10-1224 genomic DNA to generate a 1,034-bp genomic DNA fragment encompassing the integration site of pIM within the $P b c l$ locus. This fragment was sequenced directly using primers $\mathrm{P} 3$ and $\mathrm{P} 2$ to confirm the precise integration point of pIM in NH10-1224.

\section{Southern hybridization analysis.}

Conidial suspension $\left(1 \mathrm{ml} ; 1 \times 10^{7}\right.$ conidia ml $\left.{ }^{-1}\right)$ of $\mathrm{NH} 10$ and NH10-1224 was inoculated into $100 \mathrm{ml}$ of potato dextrose broth (PDB, Difco) and PDB containing hygromycin B $(\mathrm{PDBH})$ at $16 \mu \mathrm{g} \mathrm{m} \mathrm{m}^{-1}$, respectively, and incubated at $18^{\circ} \mathrm{C}$ in the dark for 3 weeks. Mycelia were harvested from the liquid culture and genomic DNA prepared according to Lee and Taylor (1990). Genomic DNA (5 $\mu \mathrm{g}$ ) was digested for $16 \mathrm{~h}$ with EcoRV or EcoRI, separated by $0.8 \%$ agarose gel electrophoresis. Southern hybridization analysis was performed following standard protocols (Sambrook et al. 1989). The blots were probed with either a 497-bp BamHI/EcoRV fragment of the $P b c 1$ coding region excised from pKD1 (Davies et al. 2000) or with HindIIIdigested pAN7-1.

\section{Cutinase induction and enzyme assays.}

Induction of cutinase activity was performed according to Davies and associates (2000). Mycelium was harvested from NH10 and NH10-1224 grown in PDB and PDBH, respectively, and inoculated into minimal medium (MM) supplemented with $0.2 \%$ apple cutin as sole carbon source and incubated, with shaking at $180 \mathrm{rpm}$ for 2 weeks in the dark. Culture filtrates were assayed for cutinase activity using p-nitrophenol butyrate (PNB) as substrate as described by Davies and associates (2000). In the plate assay, a 4-mm-diameter plug of NH10 or NH10-1224 mycelium was placed onto agar plates containing MM supplemented with $0.2 \%$ apple cutin. After incubation for 3 weeks, the colony was overlaid with $0.8 \%$ agarose containing $1.5 \mathrm{mM}$ PNB dissolved in $50 \mathrm{mM}$ sodium phosphate buffer $(\mathrm{pH} 7.0)$.

\section{RNA extraction and RT-PCR.}

Total RNA was isolated from the mycelium of $\mathrm{NH} 10$ and NH10-1224 at 0 and 4 days after induction with apple cutin, and also from $B$. napus cotyledons infected with either NH10 or NH10-1224 (5 days post inoculation), using TriPure isolation reagent (Roche Diagnostics, Lewes, U.K.). RNA (1 $\mu \mathrm{g})$ was treated with RNase-Free DNase I (Invitrogen, Paisley, U.K.) and reverse transcribed into cDNA with SuperScript II Hreverse transcriptase (Invitrogen) with Oligo (dT)12-18 in a 20- 
$\mu \mathrm{l}$ reaction mixture. First-strand cDNA $(2 \mu \mathrm{l})$ was amplified in a $50-\mu$ reaction volume with Taq DNA polymerase (Invitrogen) following the manufacturer's protocol. Primers P4 (5'-TAACAGCTCTCGGCAACAC-3') and P5 (5'-ACCAATACCAAGTCACCTCC-3'), corresponding to nucleotide positions 8 to 26 and 639 to 620 of $P b c l$, respectively, were used in the PCR to amplify a 535-bp cDNA product from $\mathrm{Pbcl}$. The identities of the RT-PCR products were verified by Southern hybridization analysis. As controls, aliquots of the first-strand cDNA also were subjected to PCR using primers G1 (5'-AGAACATCATTCCCAGCAGCAC-3') and G2 (5'-TACCGGCCTTAGCATCGAAGAC-3'), which amplify a 291-bp cDNA product from the constitutively expressed $P$. brassicae GAPDH gene (Singh 1998).

\section{Detached cotyledon pathogenicity test.}

Detached cotyledons of oilseed rape (B. napus cv. Bristol) were inoculated with $10 \mu \mathrm{l}$ of conidial suspension $\left(1 \times 10^{6}\right.$ conidia $\mathrm{ml}^{-1}$ ) of $\mathrm{NH} 10, \mathrm{NH} 10-1224$, or $\mathrm{NH} 10-1024$ and incubated for 4 weeks as described previously (Ball et al. 1992). Cryo scanning electron microcopy was carried out using an Oxford CT1500 cryo system at the Multi-Imaging Center of the University of Cambridge as described by Davies and associates (2000). Cotyledon samples were frozen to $-150^{\circ} \mathrm{C}$ in slush nitrogen and sputter coated with a 7- to 10-nm layer of gold before being scanned at $5 \mathrm{kV}$ in a Philips XL30 FEG scanning electron microscope.

\section{ACKNOWLEDGMENTS}

We thank S. Foster (Rothamsted Research, Hertfordshire, U.K.) for seed of $B$. napus cv. Bristol and for the diagnostic primers $\mathrm{Pb} 1$ and $\mathrm{Pb} 2$, I. deLorono for help with the construction of disruption vector pIM, the Royal Society for a Research Fellowship for A. M. Ashby, and the Cambridge Overseas Trust for a China Cambridge Trust Scholarship for D. Li.

\section{LITERATURE CITED}

Annis, S. L., and Goodwin, P. H. 1997. Recent advances in the molecular genetics of plant cell wall-degrading enzymes produced by plant pathogenic fungi. Eur. J. Plant Pathol. 103:1-14.

Ashby, A. M. 1997. A molecular view through the looking glass: The Pyrenopeziza brassicae-Brassica interaction. Adv. Bot. Res. 24:31-70.

Baker, E. A. 1982. Chemistry and morphology of plant epicuticular waxes. Pages 139-166 in: The Plant Cuticle. D. F. Cutler, K. L. Alvin, and C. E. Price, eds. Academic Press, New York.

Ball, A. M., Sawczyc, M. K., Ashby, A. M., Ingram, D. S., and Johnstone, K. 1991. Transformation of the fungus Pyrenopeziza brassicae, cause of light leaf spot of Brassicas, and complementation of mutants using a genomic library. Exp. Mycol. 15:243-254.

Ball, A. M., Ingram, D. S., and Johnstone, K. 1992. A detached cotyledon test for the isolation of mutants of Pyrenopeziza brassicae defective in pathogenicity determinants. J. Phytopathol. 136:204-210.

Dantzig, A. H., Zuckerman, S. H., and Andonov-Roland, M. M. 1986. Isolation of a Fusarium solani mutant reduced in cutinase activity and virulence. J. Bacteriol. 168:911-916.

Davies, K. A. 1997. Early events in Pathogenesis of Pyrenopeziza brassicae on Brassica napus. Ph.D. thesis, University of Cambridge, Cambridge.

Davies, K. A., DeLorono, I., Foster, S. J., Li, D., Johnstone, K., and Ashby, A. M. 2000. Evidence for a role of cutinase in pathogenicity of Pyrenopeziza brassicae on brassicas. Physiol. Mol. Plant Pathol. 57:63-75.

Dean, R. A. 1997. Signal pathways and appressorium morphogenesis. Annu. Rev. Phytopathol. 35:211-234.

Deising, H., Nicholson, R. L., Haug, M., Howard, R. J., and Mendgen, K. 1992. Adhesion pad formation and the involvement of cutinase and esterases in the attachment of uredospores to the host cuticle. Plant Cell 4:1101-1111.

DeJong, J. C., McCormack, B. J., Smirnoff, N., and Talbot, N. J. 1997. Glycerol generates turgor in rice blast. Nature 389:244-245.

Dickman, M. B., and Patil, S. S. 1986. Cutinase deficient mutants of Colletotrichum gloeosporioides are non-pathogenic to papaya fruit.
Physiol. Mol. Plant Pathol. 28:235-242.

Dickman, M. B., Patil, S. S., and Kolattukudy, P. E. 1982. Purification, characterization and role of infection of an extracellular cutinolytic enzyme from Colletotrichum gloeosporioides Penz. on Carica papaya L. Physiol. Plant Pathol. 20:333-347.

Dickman, M. B., Podila, G. K., and Kolattukudy, P. E. 1989. Insertion of cutinase gene into a wound pathogen enables it to infect intact host. Nature 342:446-448.

Ettinger, W. F., Thukral, S. K., and Kolattukudy, P. E. 1987. Structure of cutinase gene, cDNA and the derived amino acid sequence from phytopathogenic fungi. Biochemistry 26:7883-7892.

Foster, S. J., Singh, G., Fitt, B. D. L., and Ashby, A. M. 1999. Development of PCR based diagnostic techniques for the two mating types of Pyrenopeziza brassicae (light leaf spot) on winter oilseed rape (Brassica napus sp. oleifera). Physiol. Mol. Plant Pathol. 55:111-119.

Francis, S. A., Dewey, F. M., and Gurr, S. J. 1996. The role of cutinase in germling development and infection by Erysiphe graminis f. sp. hordei. Physiol. Mol. Plant Pathol. 49:201-211.

Gilles, T., Ashby, A. M., Fitt, B. D. L., and Cole, T. 2001. Development of Pyrenopeziza brassicae apothecia on agar and oilseed rape debris. Mycol. Res. 105:705-714.

Holloway, P. J. 1982. Structure and histochemistry of plant cuticular membranes: An overview. Pages 1-32 in: The Plant Cuticle. D. F. Cutler, K. L. Alvin. and C. E. Price, eds. Academic Press, New York.

Kolattukudy, P. E. 1984. Cutinases from fungi and pollen. Pages 471-504 in: Lipases. B. Borgstrom and H. Broakman, eds. Elsevier, Amsterdam.

Kolattukudy, P. E. 1985. Enzymatic penetration of the plant cuticle by fungal pathogens. Annu. Rev. Phytopathol. 23:223-250.

Kolattukudy, P. E., Podila, G. K., and Mohan, R. 1989. Molecular basis of the early events in plant fungus interaction. Genome 31:342-349.

Kolattukudy, P. E., Purdy, R. E., and Maiti, I. B. 1981. Cutinase from fungi and pollen. Methods Enzymol. 71:652-664.

Köller, W., Parker, D. M., and Becker, C. M. 1991. Role of cutinase in the penetration of apple leaves by Venturia inaequalis. Phytopathology 81:375-379.

Köller, W., Yao, C. L., Trail, F., and Parker, D. M. 1995. Role of cutinase in the invasion of plants. Can. J. Bot. 73:S1109-S1118.

Lebeda, A., Luhova, L., Sedlarova, M., and Jancova, D. 2001. The role of enzymes in plant-fungal pathogens interactions-Review. J. Plant Dis. Prot. 108:89-111.

Lee, S. B., and Taylor, J. W. 1990. Isolation of DNA from fungal mycelia and single spores. Pages 282-287 in: PCR Protocols: A Guide to Methods and Applications. M. A. Innis, D. H. Gelfand, J. J. Sninsky, and T. J. White, eds. Academic Press, San Diego, CA.

Longhi, S., and Cambillau, C. 1999. Structure-activity of cutinase, a small lipolytic enzyme. Biochim. Biophys. Acta 1441:185-196.

Maddock, S. E. 1979. Studies of the biology of light leaf spot disease of oilseed rape and other brassicas. Ph.D. thesis, University of Cambridge, Cambridge.

Maiti, I. B., and Kolattukudy, P. E. 1979. Prevention of fungal infection of plants by specific inhibitors of cutinase. Science 205:507-508.

Nicholson, R. L., VanScoyoc, S., Ku•, J. and Williams, E. B. 1973a. Response of detached apple leaves to Venturia inaequalis. Phytopathology 63:649-650.

Nicholson, R. L., VanScoyoc, S., Williams, E. B., and Ku•, J. 1973b. Etiolated apple hypocotyls: a useful host tissue in apple scab research. Phytopathology 63:363-366.

Parker, D. M., and Köller, W. 1998. Cutinase and other lipolytic esterases protect bean leaves from infection by Rhizoctonia solani. Mol. PlantMicrobe Interact. 11:514-522.

Pascholati, S. F., Deising, H., Leite, B., Anderson, D., and Nicholson, R. L. 1993. Cutinase and nonspecific esterase activities in the conidial mucilage of Colletotrichum graminicola. Physiol. Mol. Plant Pathol. 42:37-51.

Pascholati, S. F., Yoshioka, H., Kunoh, H., and Nicholson, R. L. 1992. Preparation of the infection court by Erysiphe graminis f. sp. hordei: cutinase is a component of the conidial exudate. Physiol. Mol. Plant Pathol. 41:53-59.

Punt, P. J., Oliver, R. P., Dingemanse, M. A., Pouwels, P. H., and van den Hondel, C. A. M. J. J. 1987. Transformation of Aspergillus based on the hygromycin B resistance marker from Escherichia coli. Gene 56:117-124.

Rawlinson, C. J., Sutton, B. C., and Muthyalu, G. 1978. Taxonomy and biology of Pyrenopeziza brassicae sp. nov. (Cylindrosporium concentricum), a pathogen of winter oilseed rape (Brassica napus subsp. oleifera). Trans. Br. Mycol. Soc. 71:441-451.

Rogers, L. M., Flaishman, M. A., and Kolattukudy, P. E. 1994. Cutinase gene disruption in Fusarium solani f. sp. pisi decreases its virulence on pea. Plant Cell 6:935-945.

Sambrook, J., Fritsch, E. F., and Maniatis, T. 1989. Molecular Cloning: A 
Laboratory Manual, 2nd ed. Cold Spring Harbor Laboratory Press, Cold Spring Harbor, NY.

Shaykh, M., Soliday, C., and Kolattukudy, P. E. 1977. Proof for the production of cutinase by Fusarium solani f. sp. pisi during the penetration into its host, Pisum sativum. Plant Physiol. 60:170-172.

Simons, A. J., and Skidmore, D. I. 1988. Race-specific resistance to light leaf spot in Brassica oleracea. Trans. Br. Mycol. Soc. 90:431-435.

Singh, G. 1998. Molecular analysis of sexual morphogenesis in the light leaf spot pathogen, Pyrenopeziza brassicae. Ph.D. thesis, University of Cambridge, Cambridge.

Singh, G., and Ashby, A. M. 1998. Cloning of the mating type loci from Pyrenopeziza brassicae reveals the presence of a novel mating type gene within a discomycete MAT 1-2 locus encoding a putative metallothionein-like protein. Mol. Microbiol. 30:799-806.

Soliday, C. L., Flurkey, W. H., Okita, T. W., and Kolattukudy, P. E. 1984. Cloning and structure determination of a cDNA for cutinase, an enzyme involved in fungal penetration of plants. Proc. Natl. Acad. Sci. U.S.A. 81:3939-3943.

Stahl, D. J., and Schäfer, W. 1992. Cutinase is not required for fungal pathogenicity on pea. Plant Cell 4:621-629.

Stahl, D. J., Theuerkauf, A., Heitefuss, R., and Schäfer, W. 1994. Cutinase of Nectria haematococca (Fusarium solani f. sp. pisi) is not required for fungal virulence or organ specificity on pea. Mol. Plant-
Microbe Interact. 7:713-725.

Sweigard, J. A., Chumley, F. G., and Valent, B. 1992a. Cloning and analysis of cut1, a cutinase gene from Magnaporthe grisea. Mol. Gen. Genet. 232:174-182.

Sweigard, J. A., Chumley, F. G., and Valent, B. 1992b. Disruption of a Magnaporthe grisea cutinase gene. Mol. Gen. Genet. 232:183-190.

Van der Vlugt-Bergmans, C. J. B., Wagemakers, C. A. M., and Van Kan, J. A. L. 1997. Cloning and expression of the cutinase A gene of Botrytis cinerea. Mol. Plant-Microbe Interact. 10:21-29.

Van Kan, J. A. L., Van't Klooster, J. W., Wagemakers, C. A. M., Dees, D. C. T., and Van der Vlugt Bergmans, C. J. B. 1997. Cutinase A of Botrytis cinerea is expressed, but not essential, during penetration of gerbera and tomato. Mol. Plant-Microbe Interact. 10:30-38.

Wang, C. L., Chin, C. K., and Gianfagna, T. 2000. Relationship between cutin monomers and tomato resistance to powdery mildew infection. Physiol. Mol. Plant Pathol. 57:55-61.

Yao, C. L., and Köller, W. 1994. Diversity of cutinases from plant pathogenic fungi: Cloning and characterization of a cutinase gene from Alternaria brassicicola. Physiol. Mol. Plant Pathol. 44:81-92.

Yao, C. L. and Koller, W. (1995) Diversity of cutinases from plant-pathogenic fungi-different cutinases are expressed during saprophytic and pathogenic stages of Alternaria brassicicola. Mol. Plant-Microbe Interact. 8:122-130. 